\title{
( \\ SERUM VITAMIN D STATUS AMONG CRITICALLY ILL CHILDREN WITH RESPIRATORY INFECTIONS
}

\begin{tabular}{l|}
\hline Dr SS \\
Kalyanshettar* \\
\hline Dr Sanjeevani \\
Umarani \\
\hline
\end{tabular}

Dr M M Patil
MD, Professor Department of Paediatrics, BLDE(DU) Shri B M Patil Medical College and Research Centre, Vijayapur Karnataka India. *Corresponding Author

MD, Resident Department of Paediatrics, BLDE(DU) Shri B M Patil Medical College and Research Centre, Vijayapur Karnataka India.

MD, Professor Department of Paediatrics, BLDE(DU) Shri B M Patil Medical College and Research Centre, Vijayapur Karnataka India.

MD, Professor Department of Paediatrics, BLDE(DU) Shri B M Patil Medical College and Research Centre, Vijayapur Karnataka India.

Dr SV Patil

ABSTRACT OBJECTIVE: To know whether low levels of vitamin D affects severity of respiratory illness and its clinical outcomes. DESIGN: Hospital based prospective cross sectional observational study.

SETTING : Pediatric Intensive Care Unit in Teaching Hospital affiliated with Medical College with study period of one and half years

METHODOLOGY: The study was performed on 50 cases of critically ill children with respiratory infectious disease admitted to the paediatric intensive care unit. Assessment of severity of respiratory infection was done with Paediatric respiratory severity score (PRESS). Serum vitamin D levels were assessed. Duration of PICU stay, hospital stay, need and type of respiratory support and its duration were also recorded.

RESULTS: Severe Vitamin D deficiency $(<20 \mathrm{ng} / \mathrm{ml})$ was noted in $64 \%$ of total cases admitted with respiratory illness in PICU. Among these, $62.5 \%$ (20) cases had severe respiratory illness. The severity of respiratory illness was found to be highly significant with low Serum vitamin D values $(\mathrm{p}<0.01)$. Low serum vitamin $\mathrm{D}$ levels were also significantly associated with length of PICU stay $(\mathrm{p}<0.01)$, length of hospital stay $(\mathrm{p}=0.014)$, type of respiratory support $(<0.001)$ and duration of respiratory support $(\mathrm{p}<0.001)$

CONCLUSION:A high prevalence of Vitamin D deficiency and insufficiency was found in critically ill children admitted with Respiratory infection. A strong statistical correlation was noted with Vitamin D deficiency and strongly associated with prolonged PICU care, respiratory support and hospitalization.

\section{KEYWORDS : Vitamin D deficiency, respiratory infection, paediatric respiratory severity score}

\section{INTRODUCTION}

Paediatric respiratory tract infections are among the most common reasons for clinicians' visits and hospitalization, and are associated with significant morbidity and mortality. [1] The acute lower respiratory infections are the major cause of hospitalizing children in paediatric intensive care unit (PICU) [2] and are an important cause of childhood death globally. "It has been estimated that more than 40 million annual deaths in the developing countries are due to acute respiratory infections, including bronchitis, pneumonia and bronchiolitis as well as a combination of these."[3] In developing countries, seven out of 10 deaths in children under 5 years of age occur due to acute respiratory tract infection (ARTI). In India, ARTI contributes to $15-30 \%$ of all under five deaths and most of these deaths are preventable. [4]

Although micronutrient deficiencies may increase the risk of ALRI ; Nutritional Vitamin D deficiency in Indian children was observed and reported as a significant risk factor for severe ARTI $-(1,4)$ Vitamin D deficiency has been associated with increased susceptibility to and severity of respiratory infections and is a modifiable risk factor in the severity of respiratory illnesses. [5]

Growing evidence suggests that vitamin D not only plays a role in calcium homeostasis but also a key role in innate and adaptive immunity and thus vitamin D deficiency has been hypothesized to be a culprit in the risk and severity of acute respiratory infection (ARI) in both adults and children. [2]

"Vitamin D deficiency has been reported to be widely prevalent in critically ill children from ICUs worldwide".[6] There is evidence from few studies that vitamin D deficiency also contribute to or prolongs critical care pathophysiology .[6-9] There are several studies which have now shown that there is an increased incidence of ARI in subjects with vitamin D deficiency [1-9] but very is little known regarding their association with severity of ARI. Whether low levels of serum Vitamin D affects the severity of illness and its outcome has been the subject of debate in pediatrics as well as adult population.

Due to the limited data available in the pediatric population and lack of interventional studies to show that administration of vitamin $\mathrm{D}$ indeed improves clinical outcomes, opinion is still divided as to whether it is just an innocent bystander or a marker of severe disease.

There may, therefore be an important role of Vitamin D in the prevention and/or treatment of respiratory infections in critically ill children. Given an evolving role of Vitamin D in respiratory health and its association with severity, our objective was therefore to estimate the levels of vitamin D in children admitted to intensive care unit (ICU) with respiratory illness and to correlate its association with duration of ICU stay and other key clinical outcome.

\section{METHODOLOGY}

This is hospital based prospective study conducted in 50 children admitted with respiratory infection in Pediatric intensive care unit. The study was approved by Institutional Ethics Committee.

All children admitted to PICU aged 1 month to 15 years with respiratory infection ( bronchitis, bronchiolitis , bronchopneumonia , tuberculosis or combination of these ) were included in the study .Those with_known or suspected adrenal, pituitary ,hypothalamic ,parathyroidism diseases, rickets, renal tubular acidosis, CKD, AKI, asthma, use of systemic steroids in the past one week, respiratory illness associated with poisoning and who lacked consent were excluded from the study

\section{Method of study:}

On admission, respiratory case fulfilling the inclusion criteria were assessed for their severity using paediatric respiratory severity score (PRESS).[10] Variables at baseline for each patient were age, gender, reason for admission, anthropometry and documentation of past respiratory illness and family history of respiratory illness were documented. Evidence of need and type of respiratory support, duration of respiratory support, duration of PICU stay and hospital stay and clinical outcome was recorded.

Within 12 hours of admission to critical care unit, blood was drawn for investigation of serum calcium, serum phosphorus, serum alkaline phosphatase and serum vitamin D. 
Blood samples collected in clot activator vials were sent to laboratory where serum was separated and vitamin D levels were estimated.

\section{Estimation of levels of serum vitamin D:}

The levels of Serum Vitamin D was estimated by CLIA (Chemiluminescence immunoassay)

Patients with serum Vitamin D levels were categorised as deficiency $(<20 \mathrm{ng} / \mathrm{ml})$, insufficiency $(21-29 \mathrm{ng} / \mathrm{ml})$ and sufficient $(30-100 \mathrm{ng} / \mathrm{ml})$ according to Endocrine Society's clinical practice guidelines. [11]. All cases were managed as per unit protocol. Levels of serum vitamin D were be correlated with the severity of illness, the length of PICU stay and total hospital stay, type of respiratory support and duration of respiratory support.

\section{Assessment of Respiratory score:}

The PRESS scoring system was used for the assessment of respiratory tract infections in children admitted in Paediatric intensive care unit. [10]

"The PRESS" assessed tachypnea, wheezing, retraction (accessory muscle use), $\mathrm{SpO}_{2}$, and feeding difficulties, with each component given a score of 0 or 1 , and total scores were classified as mild (0-1), moderate (2-3), or severe (4-5)". (Table 1)

\section{STATISTICAL ANALYSIS:}

All characteristics were summarized descriptively. Data was presented using diagrams, scattered charts, mean and standard deviation. Association between the qualitative data was measured using .chi square test and correlation between continuous variables was calculated using Spearmen's correlation. To examine factors associated with vitamin D levels logistic regression was used. Tests with $\mathrm{p}<0.05$ ( 2 sided $)$ were considered statistically significant. Analysis was performed using SPSS version 17.

\section{RESULTS}

Severity of respiratory illness for study population was graded according to Paediatric respiratory severity score.

From the table 2 , there is very strong statistical significance $(p=0.0001$ ) between severity and Vitamin D levels which highlights severe vitamin D deficiency patients have very severe respiratory illness. Hence the immunomodulatory effect of Vitamin D can be made out in our study.

\section{Length of PICU stay}

According to graph 1, the minimum duration of PICU stay is 2 days and maximum is 10 days with mean duration of 4.70 with standard deviation of 1.799 .

Applying spearmen coefficient there was statistical significance $(p=0.0001)$ noted between the length of PICU stay and Vitamin D levels of the patient.

\section{Length of Hospital Stay}

According to graph 2 the minimum duration of hospital stay is 3 days and maximum is 21 days with mean duration of 8.12 with standard deviation of 3.366 .

Applying spearmen coefficient there was statistical significance $(p=0.0001)$ noted between the length of hospital stay and Vitamin D levels of the patient.

\section{Type of Respiratory support}

Among the total number of cases admitted, 10 (20\%) cases did not require any respiratory support, while 21 cases ( $42 \%$ ) required oxygen therapy , 15 cases $(30 \%)$ were managed on CPAP and 4 cases $(8 \%)$ required ventilator support .

There is very strong statistical significance $(\mathrm{p}<0.001)$ between type of respiratory support and Vitamin D levels which highlight severe vitamin D deficiency patients have more requirement of respiratory support in the management of these patients. (Table 3 )

\section{Duration of Respiratory support}

As with graph 3 , the minimum duration of respiratory support is 0 days and maximum is 17 days with mean duration of 2.68 days with standard deviation of 2.773 .
Applying spearmen coefficient there was statistical significance $(\mathrm{p}=0.0001)$ noted between the duration of respiratory support and Vitamin D levels of the patient. (Table 4)

\section{DISCUSSION}

There is paucity of published studies in the Indian literature related to serum vitamin D deficiency prevalence among children less than 15 years with acute respiratory illness admitted to pediatric intensive care unit (PICU).

The present study was planned to determine the serum vitamin D status in critically ill patients with respiratory illness admitted to PICU and to correlate the serum vitamin D status with clinical outcomes, length of PICU stay, and total length of hospital stay, type and duration of respiratory support.

\section{Vitamin D status and severity of respiratory illness:}

From the table (25), it was found that association between serum levels of vitamin D and Severity of respiratory illness according to Pediatric respiratory severity score was statistically highly significant. This was similar to study by Wayse et al and McNally et al who found that low serum $25(\mathrm{OH}) \mathrm{D}$ levels was associated with a significantly lower risk of severe ALRI. $[12,13]$

\section{Serum vitamin D level and length of PICU stay}

The mean duration of PICU stay in this study is 4.70 days with total hospital stay duration being 8.12 days. There is statistical significance between length of PICU stay, duration of total hospital stay and serum vitamin $\mathrm{D}$ levels of the patient with $\mathrm{p}$ value being 0.014 and 0.01 respectively.

In the study done by Sankar at all, similar observations were seen with the length of PICU stay being longer in children with vitamin D deficiency with a mean difference in PICU stay of 3.5 days as compared to those who were not deficient [6].

\section{Serum vitamin D levels and type of respiratory support:}

In our study, among the 50 patients, $80 \%$ of the cases required respiratory support in the form of oxygen by nasal prongs, CPAP or invasive ventilation. The mean duration of respiratory support was 2.78 days. A strong statistical significance was noted with $\mathrm{p}<0.001$. This was similar to study by Inamo et al and Ebenezer et al children with acute lower respiratory infections who needed oxygen and ventilator management were significantly vitamin D deficient $[14,15]$.

\section{Limitation of the study:}

- Wide range of age of the study group could have affected the results of serum vitamin D levels.

- The factors affecting the vitamin D levels were not addressed.

- Several other factors which affect the length of PICU stay like sepsis, requirement of inotropes were not taken into consideration.

\section{CONCLUSION:}

- This study shows that there is a strong correlation between the severity of respiratory illness and serum vitamin D status.

- There is a positive correlation between the duration of hospital stay with serum vitamin D levels.

- The need and duration of respiratory support is seen to be higher among children with low levels of serum vitamin D.

What we know already about the study: vitamin D deficiency has been associated with increased susceptibility and is reported as a significant risk factor for respiratory illness

What this study adds: severity of vitamin D deficiency has strong correlation with severity of respiratory illness and its outcome in form of length of hospital stay and type and duration of respiratory support.

Table 1 : PRESS scoring system

\begin{tabular}{|l|l|l|}
\hline $\begin{array}{l}\text { Score } \\
\text { component }\end{array}$ & Operational definition & Scoring \\
\hline Respiratory rate & Respiratory rate at rest, on room air* & 0 or 1 \\
\hline Wheezing & $\begin{array}{l}\text { High pitched expiratory sound heard by } \\
\text { auscultation }\end{array}$ & 0 or 1 \\
\hline $\begin{array}{l}\text { Accessory } \\
\text { muscle use }\end{array}$ & Any visible use of accessory muscles & 0 or 1 \\
\hline SPO2 & $\begin{array}{l}\text { Oxygen saturation less than } 95 \% \text { on } \\
\text { room air }\end{array}$ & 0 or 1 \\
\hline
\end{tabular}


Volume - $10 \mid$ Issue - 10 | October - 2020 | PRINT ISSN No. 2249 - 555X | DOI : 10.36106/ijar

\begin{tabular}{|c|c|c|c|}
\hline Feeding & \multicolumn{2}{|c|}{ Refusing feedings } & 0 or 1 \\
\hline & \multicolumn{2}{|c|}{ Sum of five components } & \\
\hline \multirow[t]{2}{*}{ PRESS SCORE } & \multicolumn{2}{|c|}{$\begin{array}{l}\text { 0-1: mild; } 2-3: \text { moderate; } \\
\text { 4-5: severe }\end{array}$} & $0-5$ \\
\hline & Month & Respiratory rate & \\
\hline \multirow{4}{*}{$\begin{array}{l}\text { Criteria for } \\
\text { tachypnea }\end{array}$} & $<12$ & $>60$ & 1 \\
\hline & $12-35$ & $>40$ & 1 \\
\hline & $36-156$ & $>30$ & 1 \\
\hline & $>156$ & $>20$ & 1 \\
\hline
\end{tabular}
associated severity of acute lower respiratory tract infections in Japanese hospitalized children. Pediatrics International $53,199-20$

15. Ebenezer K, Job V, Antonisamy B. et al. Serum Vitamin D status and outcome among critically ill children admitted to the paediatric intensive care unit in south India. Indian J pediatr.2016;83(2): 120-5

*Respiratory rate was evaluated according to American heart association (AHA) guidelines

Table 2 :-Association between Severity of respiratory illness and Serum vitamin D level

\begin{tabular}{|l|l|l|l|l|l|}
\hline $\begin{array}{l}\text { Severity } \\
\text { (PRESS } \\
\text { SCORE) }\end{array}$ & \multicolumn{2}{|l|}{ Vitamin D level } & Total & $\begin{array}{l}\text { Chi } \\
\text { square } \\
\text { test }\end{array}$ \\
\hline & $<20$ & $20-30$ & $30-100$ & & \\
\hline Mild & $0(0 \%)$ & $8(80.0 \%)$ & $6(75.0 \%)$ & $14(28.0 \%)$ & $\mathrm{P}=0.0001 *$ \\
\hline Moderate & $12(37.5 \%)$ & $2(20.0 \% 0$ & $2(25.0 \%)$ & $16(32.0 \%)$ & \\
\cline { 1 - 5 } Severe & $20(62.5 \%)$ & $0(.0 \%)$ & $0(.0 \%)$ & $0(40.0 \%)$ & \\
\hline Total & $32(100 \%)$ & $10(100 \%)$ & $8(100 \%)$ & $50(100 \% 0$ & \\
\hline
\end{tabular}

Table 3 : association of type of respiratory support with Vitamin D levels

\begin{tabular}{|l|l|l|l|l|l|l|}
\hline \multirow{2}{*}{$\begin{array}{l}\text { TYPE OF } \\
\text { RESPIRATORY } \\
\text { SUPPPORT }\end{array}$} & \multicolumn{5}{|l|}{ VITAMIN D LEVEL CLASSIFICATION } \\
\cline { 2 - 7 } & $<20 \mathrm{ng} / \mathrm{ml}$ & $20-30 \mathrm{ng} / \mathrm{ml}$ & \multicolumn{2}{l|}{$30-100 \mathrm{ng} / \mathrm{ml}$} \\
\cline { 2 - 7 } & Count & $\%$ & Count & $\%$ & Count & $\%$ \\
\hline ROOM AIR & 0 & $0.00 \%$ & 4 & $40.0 \%$ & 6 & $75.0 \%$ \\
\hline $\begin{array}{l}\text { OYGEN } \\
\text { THERAPHY }\end{array}$ & 15 & $46.9 \%$ & 4 & $40.0 \%$ & 2 & $25.0 \%$ \\
\hline CPAP & 14 & $43.8 \%$ & 1 & $10.0 \%$ & 0 & $0.00 \%$ \\
\hline VENTILATOR & 3 & $9.4 \%$ & 1 & $10.0 \%$ & 0 & $0.00 \%$ \\
\hline Total & 32 & $100.0 \%$ & 10 & $100.0 \%$ & 8 & $100.0 \%$ \\
\hline \multicolumn{7}{|c|}{ Chi-square value $=27.76 ; \mathrm{P}<0.001$} \\
\hline
\end{tabular}

Table 4: Correlation between length of PICU stay, length of Hospital stay and duration of respiratory support with Serum Vitamin D

\begin{tabular}{|l|l|l|}
\hline Correlation between & $\begin{array}{l}\text { Spearman's } \\
\text { Correlation } \\
\text { coefficient (r) }\end{array}$ & P value \\
\hline $\begin{array}{l}\text { Serum vitamin D and Length of PICU } \\
\text { stay }\end{array}$ & $\mathrm{r}=-0.738$ & $\mathrm{P}=0.0001 *$ \\
\hline $\begin{array}{l}\text { Serum vitamin D and Length of hospital } \\
\text { stay }\end{array}$ & $\mathrm{r}=-0.512$ & $\mathrm{P}=0.0001 *$ \\
\hline $\begin{array}{l}\text { Serum vitamin D and Duration of } \\
\text { Respiratory support }\end{array}$ & $\mathrm{r}=-0.784$ & $\mathrm{P}=0.0001 *$ \\
\hline
\end{tabular}

\section{REFERENCES}

1. Alladi YR, Gopal J. Vitamin -D Deficiency and Relation to Recurrent Respiratory Tract Infection in children less than 5 years. IOSR - JDMS. 2017;16(8):88-96.

2. Chauhan JC, Slamon NB. The impact of multiple viral respiratory infections on Chauhan JC, Slamon NB. The impact of multiple viral respiratory infectio
outcomes for critically ill children. Pediatr Crit Care Med. 2017;18(8):e333-8.

3. Khakshour A, Farhat AS, Mohammadzadeh A, Zadeh FK, Kamali H. The association between 25 -dehydroxy vitamin $\mathrm{D}$ and lower respiratory infection in children aged less than " 5 " years in Imam Reza hospital, Bojnurd, Iran. 2015;65(11):1153-5.

4. Jyothi A, Reddy S, Dayanand C. Association of serum vitamin d levels with severity of acute respiratory tract of Biochemistry, Sri Devaraj. Int J Curr Res. 2017;9(04).

5. Jain P, Wiles A, Chamberlain M, Freishtat RJ. Vitamin D in Pediatric Inpatients With Respiratory Illnesses. An official journal of the American Academy of Pediatrics. $2017 ; 25$.

6. Sankar J, Lotha W, Ismail J, Anubhuti C, Meena RS, Sankar MJ. Vitamin D deficiency and length of pediatric intensive care unit stay: a prospective observational study. Ann and length of pediatric intensive care unit stay: a prospective observational study. Ann Intensive Care. 2016;6(1):1-9.

7. Ginde AA, Mansbach JM, Camargo CA Jr. Association between serum 25dydroxyvitamin D level and upper respiratory tract infection in the Third National Health and Nutrition Examination Survey. Arch Intern Med 2009; 169:384-90.

9. Menon K, Chakraborty P, Williams KA, Osama Y, Doherty DR. The Association of Vitamin D Status With Pediatric Critical Illness. 2017;130(3):429-36.

10. Miyaji Y, Sugai K, Nozawa A, Kobayashi M, Niwa S, et al. Pediatric Respiratory Severity Score (PRESS) for Respiratory Tract Infections in Children. Austin Virol and Retrovirology. 2015;2(1): 1009.

11. Holick MF,Binkley NC,Bischoff-Ferrari HA, et al(2011)evaluation treatment and prevention of vitamin D deficiency; an endocrine society clinical practice guideline.J Clin Endocrinal Metab 96,1911-1930.

12. Wayse V, Yousafzai A, Mogale K, et al. (2004)Association of subclinical vitamin D deficiency with severe acute lower respiratory infection in Indian children under $5 \mathrm{y}$. European journal of clinical nutrition 58,563-567.

13. McNally JD, Leis K, Matheson LA, et al. (2009)Vitamin D deficiency in young children with severe acute lower respiratory infection. Pediatr Pulmonol 44,981-988

14. Inamo Y, Hasegawa M, Saito K, et al. (2011) Serum vitamin D concentrations and 